\title{
In Search of Fairness: Critical Design Alternatives for Sustainability
}

\author{
Somya Joshi \\ Stockholm University \\ Borgarfjordsgatan 12 \\ somya@dsv.su.se
}

\author{
Teresa Cerratto Pargman \\ Stockholm University \\ Borgarfjordsgatan 12 \\ tessy@dsv.su.se
}

\begin{abstract}
Does fairness as an ideal fit within the broader quest for sustainability? In this paper we consider alternative ways of framing the wicked problem of sustainability. One that moves away from the established preference within HCI, towards technological quick-fixes. We adopt a critical lens to challenge the belief that by merely changing practices at an individual level one can do away with unsustainability. This thinking, we argue, is flawed for many reasons, but mostly because of the wickedness of the sustainability problem. By analyzing the case of Fairphone, we illustrate how it is possible to imagine and design change at a broader level of community engagement, when it comes to concerns of fairness and sustainability. We contribute to a deeper understanding of how social value laden enterprises along with open technological design can shape sustainable relationships between our environment and us.
\end{abstract}

\section{Author Keywords}

Sustainability; Open Technologies; Critical Alternatives;

Transactions; Social-Ecology.

\section{ACM Classification Keywords}

H.5.m. Sustainable interaction design, Miscellaneous.

\section{INTRODUCTION}

How do we build systems that are in line with current understandings of Earth's finite natural resources? How do we design them to catalyze and sustain social change? These and other questions have been introduced and developed within the Sustainable HCI (SHCI) literature $[3,17,8,18,14,10,20,24]$. This pioneering body of research work has drawn on theoretical and applied developments that can be related to third wave HCI [5]. They have on the one hand, touched upon key issues related to our everyday practices and culture and, on the other hand, they have overflowed third wave HCI boundaries as they are not only focused on the cultural, emotional, pragmatic or historical

Copyright $(2015$ is held by the author(s). Publication rights licensed to Aarhus University and ACM

5th Decennial Aarhus Conference on Critical Alternatives

August $17-21,2015$, Aarhus Denmark

DOI: http://dx.doi.org/10.7146/aahcc.v1i1.21301 levels of human experience [5], but are also deeply concerned by environmental [1], socio-political [13], social sustainability [4] and ecological concerns [20]. Latest developments in Sustainable HCI (SHCI) clearly indicate an interest into the development and design (or undesign) of technologies relying less on instrumental purposes of efficiency connected with corporate profit [17] and more prone on volitional and value-laden aspects underlying people's use of technologies [6,2]. Our paper follows from the above, focusing primarily on the social value laden enterprise and its processes of activism and co-creation that inform critical alternatives within the SHCI discourse. We do so via the illustrative lens of a case study (Fairphone [10]) that enables us to conceptualise technological design and consumption from a holistic perspective of social ecology. The paper contributes with four critical design alternatives towards sustainability.

\section{THEORETICAL UNDERPINNINGS}

Our interest in the social ecology perspective [16,21] is due to its holistic understanding of the interplay between natural-ecological and socio-semiotic dimensions. In particular, we turn our attention to how this interplay of dimensions can be reflected in the design process. This relationship, we believe, is key to further elaborate on issues pertaining to the design and building of computer systems [7]. In particular, this specific relationship between material (natural) and human (constructed) facets of human-environment systems is referred to as transactions [21]. By transactional relationships, Stokols et al. [21] refer to continuous, bidirectional and mutually influencing relationships occurring between both natural-ecological (i.e. material) and social-semiotic dimensions (i.e. meanings, values, moral judgments). Transactions entail exchanges among diverse actors, assets and resources that play a major role in the sustainability and resilience of our environment. A particularity of these transactions is that they are not fungible, as changes in one dimension are related to changes in another dimension. As such, the concept of transaction has implications for SHCI in terms of how we think about the delineation and understanding of the design space. We see it as an arena wherein diverse compromises are made as a result of the multiple and multifarious dilemmas [15] designers are confronted with, when dealing with sustainability issues. 


\section{FROM THEORY TO PRAXIS: THE FAIRPHONE ROADMAP}

Based on the theoretical discussion above, we set out to examine what such an alternative might look like in practice. Fairphone started off as an awareness raising campaign in 2010, mainly focused on conflict minerals within the context of the smartphone industry. In the absence of a real alternative to point to, Fairphone emerged as a social enterprise in 2013, as the outcome of a crowdfunded campaign designed to produce a truly 'fair' phone. While the notion of fairness here was co-constructed by the founding members and the community of users, the four main action points that the movement was built around, were: mining, manufacturing, design and life-cycle. We chose this case as it provides us with a window into two worlds simultaneously: that of a social enterprise setting out to engineer and sustain a movement (based on changing relationships and practices within the domain of technology design and consumption), and, that of a technical artifact designed to embody the life-cycle approach - built on the "fairware" principles (open hardware and software, conflict free and fair in terms of workers rights, circular economy - a "cradle to cradle" approach).

\section{Empirical Design}

This paper draws on data collected at two levels. Primary: of semi-structured interviews conducted iteratively, with impact development and product strategy staff at Fairphone. Secondary: data collected via the website, blogs and online documentation, as well as the critical voices emerging from the wider community of users and supporters. The latter consists of early adopters, experts, users, designers and partner organisations. We also draw on social media data from Twitter (\#wearefairphone) and Facebook. The analysis of the data was conducted using a procedure known as explication de texte, or close reading, an analytical method that originated in the humanities [19]. We took into consideration texts (i.e. interview transcripts, expert reports, blog entries, social media excerpts and forum debates) as our unit of analysis, from which we arrived at conceptual threads. They constitute the findings of our study, which we will unpack in the following section.

\section{Performing Fairness}

Defining the landscape of fairness is a tricky task, given that there is neither a single accepted definition, nor an absolute state of fairness per se. As a concept it is construed both in terms of procedural and distributive fairness [11]. It is the latter, equity-based logic for action, which concerns us the most within this inquiry, with respect to responsibilities and resource distribution. The global resource challenge shifts from being a matter of "living within limits" to one of "living in balance" between social and environmental boundaries [12]. Fairness is situated within an ecosystem of ideals aspired to by society, such as sustainability, freedom, justice, peace, truth. None of these concepts exist in an absolute state; rather the incremental enactment of re-balancing the inherent inequity is what we focus on. To address the above, we consider alternative ways of framing the wicked problem of sustainability. One that moves away from the established belief within HCI, in technological quick-fixes. We adopt a critical lens to challenge the belief that by only changing behavior at an individual level, one can do away with unsustainability. This thinking, we argue, is flawed for many reasons, but mostly because of the wickedness of the sustainability problem. By analyzing the case of Fairphone, we illustrate how it is possible to imagine and design change at a broader level of community engagement, when it comes to concerns of fairness and sustainability.

\section{CRITICAL DESIGN ALTERNATIVES}

From the data analyzed, the following four themes emerged.

\section{From a logic of Volume to a logic of Fairness}

Design alternatives in some cases are based on the principle that change arises when technologies provide opportunities for individuals to live differently [22]. Sustainability in this context is a byproduct of the artifact itself. Other design choices frame change-making as arising from technology providing opportunities for community debate [9], in which the direction for change is set by communities themselves. Within the context of Fairphone, we observed both these drivers for change. Framing itself as a social enterprise, Fairphone has at the outset opted for a mandate that is more rooted in the ethics of sustainability than in any desire to be industry leaders in the smartphone domain. This has translated into a set of compromises or trade-offs. As a young start up, it has found itself in the position where it is unable to diversify its product range, or maximize much needed profits in order to grow; but instead keep a steady focus on the goal at hand which is to promote fairness and quality control of the existing artifact. In the words of the CEO of the organization, "Our mission is to create momentum to design this future. We started by making a phone to uncover production systems, solve problems and use transparency to invite debate about what's truly fair. We believe that these actions will motivate the entire industry to act more responsibly." Two years down the line, "This is where we still are. Our business model hasn't changed, nor has our product focus - we will still concentrate on phones, and won't branch out into other consumer electronics like laptops or tablets." While this model has so far worked well for Fairphone, we are skeptical about the transferability and sustainability of this approach for other young start ups operating within a highly competitive market (without the same safety-nets). Another reservation we have pertains to the measurable impacts emerging from 
this choice to prioritize fairness over profits or growth. In particular we wonder how this translate into tangible changes within the established industry of consumer electronics, where it remains to be seen if the model of Fairphone serves as an inspiration for change or a niche alternative which leaves no dent in their operations.

\section{From Technology Quick-Fixes to Changing Relationships}

Just as DNA comes in pairs, we were informed in our discussion with the Head of Impact at Fairphone, that the DNA of this social enterprise consists of two strands: on the one hand, it aims to change the relationship between users and how they consume technology, on the other hand, it aims to use technology as an innovative tool to alleviate societal problems that emerge from its supply chain. From our critical standpoint, we see two key challenges standing in the way of realizing the goal of changing relationships between users and their technology fixes. That of scalability and the slow pace of change within the sustainability context. With regard to the former, a small outfit such as Fairphone (i.e. 30 fulltime staff in Amsterdam) simply (to put it in their own words) "can not afford to move the entire supply chain of production from China to Europe." This alludes to a set of compromises that shift their roadmap and milestones to impacts more graspable, small scale and localized in the early stages of development. With regard to the latter challenge, in an industry and market such as that of smart phones and more broadly consumer electronics, the rate of change in product development feeds into an expectation of heightened novelty seeking. One member of the team, working on product design, commented that it was not just the consumer, with whom the relationship was transforming, but also with industrial traders (such as for example telecom providers and plastic suppliers) who were coming to view Fairphone as an experiment they increasingly sympathized with. It provided them proof that an alternative could exist. Within this environment, we ask, what does it entail to engage in a slow deliberate march towards the attainment of sustainability goals, most of which are not immediately apparent (i.e. changing worker relationships, acceptance of standards and regulation with regard to conflict free mining, recycle-reuse impacts)?

\section{From Locked-in Design to Collaborative Co-creation}

With regard to the actual technical artifact at hand, Fairphone has positioned itself along a roadmap towards 'Fairware', which is a concept expressed in both long and short term ideas. Thinking short term, Fairphone aims at being open source to allow lead users to optimize it, as well as modular, so others can repair/replace parts to use the phone longer. In the long term, "Cradle2Cradle" design would enable reuse scenarios, where old modules could be used to upgrade other devices, which would allow circulating across product cycles. This would considerably cut down on waste and forced obsolescence in the long term. This links to our understanding of critical alternatives, in that it provides a mechanism to challenge the status quo with regard to consumption choices and locked-in design (i.e. proprietary systems that engender waste and unsustainability in their wake). During our interviews with the team, we were provided with the following view on both the evolution of the artifact and the movement: "Today Fairphone is not for everyone. The early adopters or aware consumers are the ones who are part of the community, because either they are interested in conflict minerals, or workers rights, or environmental impact. However by joining the movement, they gain a context to this awareness and see the bigger-linked picture of the life cycle approach we adopt. We are essentially providing them with the tools to be curious with." The cocreation then takes place, we argue, not just at the level of the product design, but also in terms of education and capacity building on the part of the wider Fairphone community. The trade offs of opening up both the technical design of the phone and the future evolution of it to the wider user community, are manifold. Sustainability in hardware choices translated into decisions such as the modularity of the phone, its openness to friendly hacks and the conflict free nature of materials used, all make costly demands on resources, that are otherwise spent on user experience (e.g. larger screens, lighter phones, cheaper and faster processors, better cameras etc.) By adopting a lifecycle view, and interlinking design as well as consumption decisions made closer to home, with impacts in far away and often disconnected places, the very discourse of innovation and sustainability are being reexamined and reworked.

\section{Opening up the 'black box' of design}

One startling difference we found between the model adopted by Fairphone and mainstream consumer electronics manufacturers, concerns the openness in design and the holistic life-cycle view. Be it manifest in the urban mining workshops organized routinely or the e-waste reduction efforts in Ghana, the attempt here is one of creating conditions for debates around sustainability. Urban mining emerges from this context as a way to change the existing imbalance, by the extraction of minerals from existing products. The aim is to dismantle gadgets that have reached their end-of-life to uncover what's within. The idea is that once users have unscrewed the back cover of their technological artifact (in this case a smart phone), and identified the components, the urban mining workshop would aim to unravel some of the phone's hidden stories. From pollution and extremely dangerous working conditions to child labor, one can learn that a number of mining-related practices desperately require improvement. The approach adopted by mainstream players within this context, is to hide this inconvenient body of knowledge behind, sealed, glued and proprietary locked in devices, where the design serves as an impenetrable casing which keeps all unpalatable, guilt- 
inspiring footprints of our consumption behaviours, neatly out of sight (and hence out of mind). The critical alternative being offered by Fairphone here is one of opening the design processes.

\section{CONCLUSION}

Far from being a flawless and self-contained movement, Fairphone is in its early stages of evolution, experiencing the teething pains expected of any initiative aiming to challenge the status quo. We see it as a step towards opening the discourse of critical alternatives within sustainable HCI. In this paper we have presented critical alternatives, both at the theoretical level (with the socioecological approach as a lens) and at an applied level (via the illustrative lens of the Fairphone case). In doing so we have contributed to a more holistic understanding of how social value laden enterprises along with open technological design can shape sustainable relationships between our environment and us.

\section{REFERENCES}

1. Aoki, P.M.; Honicky, R.J.; Mainwaring, A.; Myers, C.; Paulos, E.; Subramanian, S. and Woodruff, A. A Vehicle for Research: Using Street Sweepers to Explore the Landscape of Env. Community Action. In Proc. CHI'09 ACM (2009), 375-384.

2. Bellotti, V., Caroll, J.M. and Kyungsik, H. Random acts of kindness: The intelligent and context-aware future of reciprocal altruism and community collaboration. In Proc. of CTS. IEEE (2013), 1-12.

3. Blevis, E., Makice, K., Odom, W., Roedl, D., Beck, C., Blevis, S., and Ashok, A.: Luxury and new luxury, quality and equality. In Proc. DPPI '07, ACM (2007), 296-311.

4. Busse, D.; Blevis, E., Beckwith, R.; Bardzell, S.; Sengers, P.; Tomlinson, B.; Nathan, B. Social Sustainability: An HCI Agenda. In Proc. CHI EA'12. ACM (2010), 1151-1154.

5. Bödker, S. When second wave HCI meets third wave challenges. In Proc. NordiCHI '06, ACM Press (2006), 1-8.

6. Cerratto-Pargman, T. A European strand of Sustainable HCI? Workshop paper NordiCHI '14. (2014). http://www.researchgate.net/publication/276206198 Understa nding Limits from a Social Ecology Perspective

7. Cerratto Pargman, T. and Joshi, S. (2015).

Understanding limits from a social ecology perspective. LIMITS 2015, Irvine, CA. USA http://www.limits2015.org/papers/limits2015-cerrattopargman.pdf
8. DiSalvo, C., Sengers, P., and Brynjarsdòttir. Mapping the landscape of sustainable HCI, In Proc. CHI'10. ACM (2010), 1975-1984.

9. DiSalvo, C. Adversarial design. MIT Press, 2012

10. Fairphone. www.fairphone.com

11. Haidt, J. (2012). The righteous mind. Why good people are divided by politics and religion. Random House.

12. Hajer, M.; Nilsson, M.; Raworth, K.; Bakker, P.; Berkhout,F.; de Boer, Y., Rockström, J.; Ludwig, K. and Kok, M. Beyond Cockpit-ism: Four Insights to Enhance the Transformative Potential of the Sustainable Development Goals. Sustainability 2015, 7, 1651-1660.

13. Dourish, P. HCI and Environmental Sustainability: The Politics of Design and the Design of Politics. In Proc. DIS'10, ACM Press (2010),1-10.

14. Håkansson, M. and Sengers, P. Beyond Being Green: Simply Living Families and ICT. In Proc. CHI ' 13 . ACM (2013). 2725-2734.

15. Håkansson, M. and Sengers, P. (2014). No easy compromise:Sustainability and the dilemmas and dynamics of change. Proc. of DIS'14. ACM (2014).1025-1034.

16. Lejano, R. and Stokols, D. Social Ecology, Sustainability and Economics. Ecological Economics, 89 (2013), 1-6.

17. Nardi, B. The Role of Human Computation in Sustainability, or, Social Progress is Made of Fossil Fuels. In Handbook of Human Computation, New York, Springer, 2013.

18. Pargman, D. and Raghavan, B. Rethinking sustainability in computing: from buzzword to nonnegotiable limits. In Proc. NordiCHI'14. ACM (2014), 638-647.

19. Richards, I.A. (1930). Practical Criticism. A study of Literary Judgment. Kegan Paul \& Co.Ltd. London.

20. Silberman, S. and Tomlinson, B. Toward an Ecological Sensibility. In Proc.CHI '10 EA. ACM (2010), 34693474.

21. Stokols, D., Lejano, R. and Hipp, J. Enhancing the Resilience of Human-Environment Systems: a Social Ecological Perspective. Ecology and Society 18, 1 (2013), 1-12.

22. Woodruff, A., Hasbrouck, J., and Augustin, S. A bright green perspective on sustainable choices. In Proc. $\mathrm{CHI}$ '08. ACM (2008).313-322. 